\title{
Breakfast habits, nutritional status and their relationship with academic performance in elementary school students of Tehran, Iran
}

Fahimeh Soheilipour ${ }^{1}$, Hamid Salehiniya ${ }^{2,3}$, Mostafa Farajpour.kh ${ }^{1}$, Mohadeseh Pishgahroudsari ${ }^{1}$

1) Minimally Invasive Surgery Research Center, Iran University of Medical Sciences, Tehran, Iran

2) Zabol Medical Science University, Zabol, Iran

3) Epidemiology and Biostatistics Department, School of Public Health, Tehran University of Medical Sciences, Tehran, Iran

\section{DOI: $10.15386 /$ cjmed-956}

Manuscript received: 30.12 .2017 Received in revised form: 27.07.2018 Accepted: 08.10.2018

Address for correspondence: pishgah.m@iums.ac.ir

\begin{abstract}
Background. The aim of this study was to examine the breakfast habits, nutritional status and their relationship with academic performance in primary school students in Tehran, Iran.
\end{abstract}

Method. In this cross-sectional study 829 primary school children were included. Child Body Mass Index (BMI) was calculated based on the objective measures of height and weight as well as adjusted for age and gender. Data on Breakfast habits and academic performance were collected by a valid checklist. For data analysis we used Chi-squared and Fisher's exact test using SPSS software, version 11.5; statistical significance was assumed if $p$-value is below the 0.05

Results. The average breakfast consumption per week was 5.5 times (days) with a standard deviation of 2.9. Based on the results, $30.9 \%$ of participants did not consume full breakfast (six times or less) and $69.1 \%$ had a complete one. In terms of academic grade level, $88.4 \%$ of the participants were in a high level, $10.3 \%$ in appropriate conditions and only $1.3 \%$ of the respondents required more effort (inappropriate).There was no significant correlation between breakfast consumption and academic status $(\mathrm{p}=0.73)$, nutritional status of the participants according to the academic performance status Individuals showed no statistically significant relationship $(\mathrm{P}=0.9)$.

Conclusion. Unlike previous studies, this study revealed no correlation between the academic grade level of elementary students with nutritional status and breakfast habits. It is suggested that according to the qualitative school scoring method, future studies are needed to assessing the students' academic performance. Other parameters will be considered in addition to the average in order to provide a better perspective of students' academic performance.

Keywords: body mass index, children, obesity, breakfast, Iran, students, academic performance

Today's increasing prevalence of obesity and overweight in childhood has become a global health concern [1] and considered as an epidemic issue in the community [2-4]. According to statistics in studies around the world, there are 43 million overweighed and obese children [5].

Obesity and overweighting in children are also a considerable problem in Iran, and there is an increasing growth of prevalence of obesity among children in Iran comparing to other countries. [6,7] .Obesity and overweight in childhood are associated with significant outcomes such as obesity at older ages, diabetes, hypertension and stroke in adulthood [8-12]; also studies show the effects of obesity on the increased risk of mortality and reduced life expectancy [13].
Most of the non-communicable diseases are rooted in childhood and overweight at this age group and on the other hand, healthy diet and eating habits, the nutritional status and breakfast consumption are the most important factors influencing the status of obesity and health during childhood. The most effective factor is the child's weight status [14]. Good nutrition is a "cornerstone of good health" as described by the World Health Organization [15]. Healthy and fit nutrition is one of the prominent prevention of obesity in children and their youth [16], since at this specific age children are growing and they need proper and healthy nutrition to have proper growth conditions [17]. Also, schoolchildren are more active, so they 
are in greater need for good nutrition [18]. Solid evidence exists that inadequate nutrition is related with hindered growth and delayed mental advancement [19].

Healthy nutritional diet at a young age ensures better development and health status in the coming years of a person's life [16]. Regular breakfast consumption would be an important remedy to obtain adequate calorie intake and healthy lifestyle later at a younger age [20]. Breakfast is a basic requirement for children and needs to be introduced in school in order to improve the nutritional security of children. In this regard, breakfast is recommended in schools $[21,22]$, in order to obtain cognitive function, reduce stress and obesity problems [22], increase the child's academic performance [23] and reduce obesity and overweight [24]. Whenever children's essential nutrition and wellness needs were considered, they have the intellectual vitality to learn and accomplish higher grades in school [25].

A child that is all around sustained with an adjusted eating routine will increment in weight and such child additionally includes in some sort of activity to keep the body fit [26].

Skipping breakfast can also indirectly affect child academic performance, by this we mean that if children considered breakfast consumption at this age it would greatly reduce the risk of obesity [14] which is an obstacle to students' academic performance [27]. Since the nutritional status and dietary habits of children can be effective in the health of the individual and have harmful consequences [28], regular breakfast consumption is recommended at different ages, especially at early childhood [29]. Shortage of food is known as one of the most important barriers to learning in school [30]; according to studies in Iran, a large percentage of students go to school without breakfast, and those who have eaten breakfast may have sometimes not high quality breakfast [31]. Eating breakfast is not common among people, especially children [14]. Turning to possible solutions, an obvious step would be proposing breakfast programs at the school to improve students 'academic and cognitive performance and this seems to have a positive impact on students' academic performance [30]. But it remains with no such plan in Iran. Considering the importance of eating breakfast at school age and the need for information for planning and decision making, and the lack of comprehensive study in this field in the country, this study aimed to investigate the status of breakfast habits, nutritional status and its relationship with the academic performance of elementary school students in Tehran during the academic year 2016.

\section{Materials and methods}

\section{Study design and sampling}

This cross-sectional study was conducted among elementary school students in the age range of 8 to 12 years in Tehran. Multi-stage sampling was used to select the samples. First, Tehran was divided into five sections: North, South, East, West and Central. Then, by referring to the Ministry of
Education in each region, a list of profit and nonprofit schools was provided. Two elementary schools were selected using a simple random sampling method from each region, so a total of 10 elementary schools were included in the study (5 profit and 5nonprofit schools). The elementary school in Iran is composed of six years, so, a selection of six classes was randomly selected from each school, and all students were invited to participate in this study. Students with any chronic disease (for example malignancy, diabetes, heart disease, kidney disease) were excluded from the study.

\section{Measurements and data collection}

SECA digital weighing scale was used for body weight measurement, in this situation, students had minimum clothes and no shoes during scaling. Also SECA body meter used for Height measurement and during scaling student's stands without shoes with normal position of the shoulder.

MedCalc 3000 system were used to determine BMI-for-age (BMI Z-score) and body weight status of respondents. BMI-for-age was classified into four groups, including underweight ( $<5$ percentile), healthy weight $(\geq 5$ percentile to $<85$ percentile), over weight ( $\geq 85$ percentile to $<95)$, and obesity ( $\geq 95$ percentile) [32].

Data on Breakfast habits and academic performance was collected by checklist including frequency of breakfast consumption per weak and Academic performance was asses by academic grade level including Excellent, Good and Need more effort, this checklist approved by expert and finalized in pilot study.

\section{Data collection}

Firstly, the study protocol was approved by the Medical Research Ethical Committee of Obesity Research Center of Minimally Invasive Surgery, Iran University of Medical Science.

In addition, approvals were acquired from the Ministry of Education in Tehran and selected schools. Signed consents were obtained from both children and their parents and checklist were distributed to them. All checklists were completed anonymously.

A total of 920 children with their parents were invited to participate in this study; 53 students were excluded from study because of chronic diseases ( 2 for anemia, 1 for migraine, 1 for Chronic Kidney Disease (CKD), 1 for kidney stone, 5 for heart disease, 2 for Glucose-6phosphate dehydrogenase, 2 for recurrent Urinary tract infection (UTI), 1 for nocturia, 2 for chronic sinusitis, 2 for Gastroesophageal reflux disease, 3 for diabetes, 2 for hypothyroidism, 2 for epilepsy, 1 for thalassemia, 11 for asthma and 15 for allergies), and 13 other students were excluded because of incomplete information. Finally, a total of 829 children and their parents participated in this study.

\section{Data analysis}

We used SPSS (Statistical Package for Social Sciences, V 11.5) program for Statistical analysis. Mean and standard deviation were calculated for quantitative variables and frequency (percent) describes qualitative variables. For data 
analysis we used chi square or Fisher's Exact, p value less than 0.05 was accepted as indicating statistical significance.

\section{Results}

In this study, 829 children entered the final analysis, the mean age of the participants was 9.77 with a standard deviation of 1.48 with the range of 8 to 12 who were 463 (55.9\%) of girls and $366(44.1 \%)$ boys. According to the World Health Organization classification, $7.4 \%$ of students were underweight, $20.6 \%$ were overweight and $14.6 \%$ were obese respectively.

The average breakfast consumption per week was 5.5 times with a standard deviation of 2.9. Based on the results, $30.9 \%$ of participants did not consume full breakfast (Six days or less than 6 in week (or less) and $69.1 \%$ had full breakfast.

In terms of academic grade level, $88.4 \%$ of the participants were in a high level and $10.3 \%$ in good condition and only $1.3 \%$ of the respondents needed more effort (inappropriate).

The prevalence of obesity in people who did not have full breakfast was $18 \%$, in contrast to those who consumed breakfast, which had $13.1 \%$ obesity, the prevalence of overweight in those who did not consume full breakfast was not statistically significant $(p=0.1)$, figure 1 shows the distribution of nutritional status in terms of breakfast consumption.

In those who did not consume full breakfast, $1.2 \%$ had an inadequate academic grade, and in the group that consume full breakfast, $1.6 \%$ of the participants were inadequate for an academic grade, In addition, the percentage of those who scored an excellent score was even more in the group of incomplete breakfast consumption than in the full breakfast group (89\% vs. $87.1 \%)$. There was no significant relationship between breakfast consumption and academic status in the 2 groups of study $(\mathrm{P}=0.73)$ (Figure 2 ).

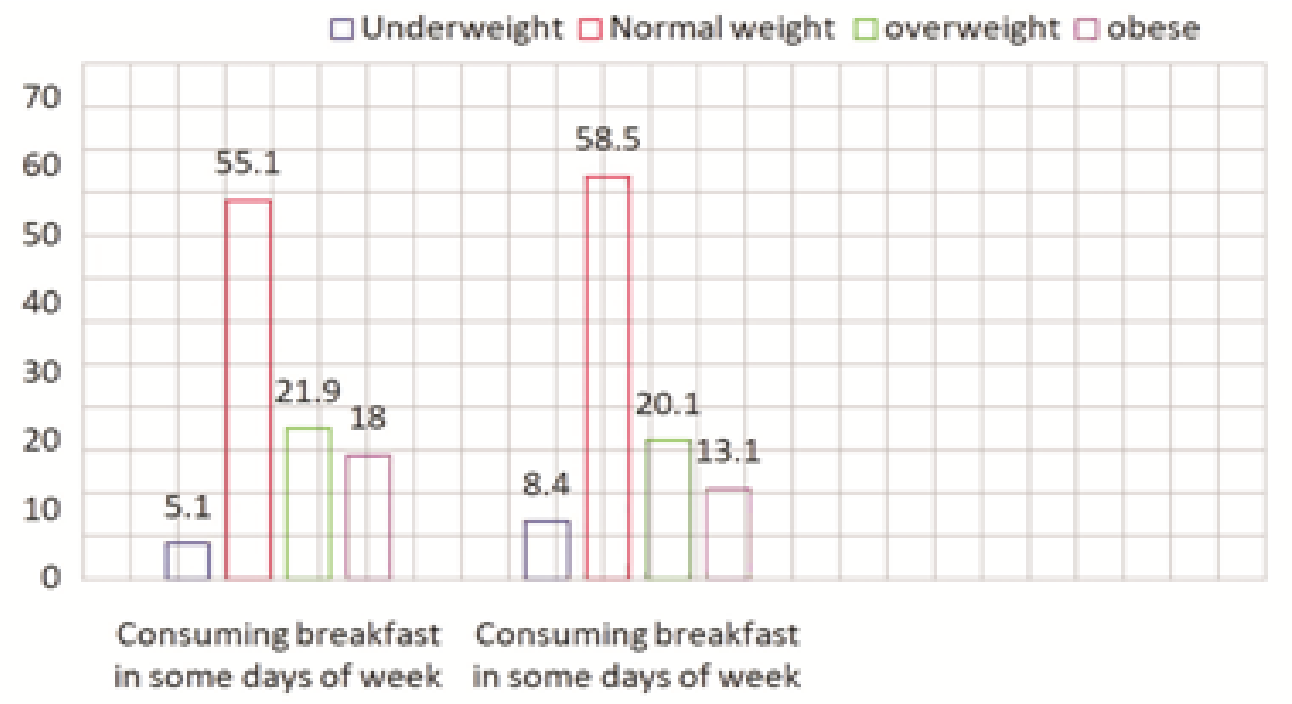

Figure 1. BMI (Body Mass Index) status of participants based on breakfast consumption status (value reported in percentages)

Excellent $\square$ Good $\square$ Needmore effort

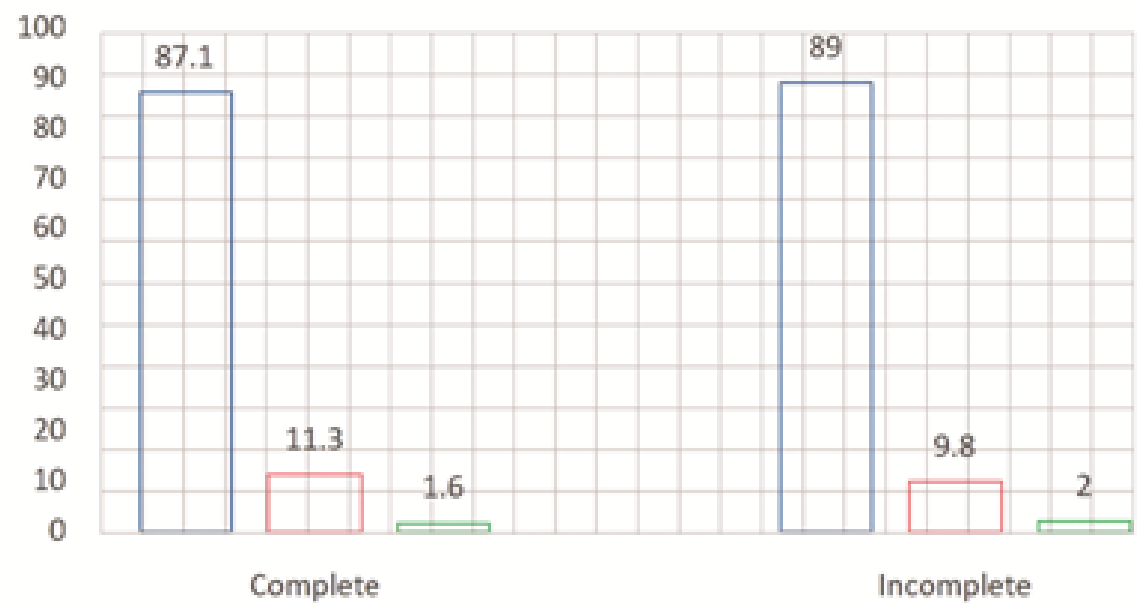

Figure 2. Academic status based on breakfast consumption (value reported in percent). 
Table I. The Body Mass Index (BMI) status of the participants studied based on the academic performance status.

\begin{tabular}{lc|c|c|c} 
BMI status & $\begin{array}{c}\text { Excellent } \\
\text { N (Percent) }\end{array}$ & $\begin{array}{c}\text { Good } \\
\text { N (Percent) }\end{array}$ & $\begin{array}{c}\text { Need more effort } \\
\text { N (Percent) }\end{array}$ & P value \\
Underweight & $54(7.4)$ & $7(8.2)$ & 0 & \\
Normal weight & $421(57.4)$ & $48(56.5)$ & $7(63.6)$ & 0.9 \\
Overweight & $149(20.3)$ & $20(23.5)$ & $2(18.2)$ & \\
Obese & $109(14.9)$ & $10(11.8)$ & $2(18.2)$ & \\
\hline Total & $733(100)$ & $85(100)$ & $11(100)$ & \\
\hline
\end{tabular}

According to the results of this study, there is an increased prevalence of obesity among children who had a higher educational level (undesirable) than those with a desirable academic status. Table I shows the nutritional status of the participants according to the academic performance status. The relationship between nutritional status of the participants and academic performance status was not statically significant.

\section{Discussion}

Primary education is an important stage in the advancement of consciousness and identity of the child as it is considered to be a bridge to the outside [33]. At this stage of advancement, children are amazingly curious and primary education must encourage this inclination among the children from different ethnic, cultural, and socioeconomic background [34].

Genetics and nutrition might be dependable on the variations that happen in early developmental abilities of children $[35,36]$.

One of the prominent nutritional aspects which affects education of children is breakfast consumption, which has been evaluated for mental function, physical activity, attending school and enhancing memory in remembering information in various researches [37].

The pattern of breakfast consumption varies according to the variety of socioeconomic factors in different societies. In Tehran, due to cultural and ethnic diversity, breakfast consumption and its effective factors can be considered in different aspects. Based on the results of this study, $30.9 \%$ of participants did not consume full breakfast (six times or less) and $69.1 \%$ had full breakfast. The data on the lack of breakfast in elementary school students in Tehran in the years 1997 and 2005 were reported to be $4.6 \%$ and $6.6 \%$ respectively $[38,39]$.

Also, a study conducted in the city of Langroud (a city in north of Iran) in the year of 2008 revealed that $8 \%$ of the elementary school students had shortage of breakfast consumption [40]. In Golestan and Zahedan, these figures were $8 \%$ and $2.5 \%$ in two separate studies respectively $[24,41]$.

A study conducted in Maryland, USA, also showed that breakfast was not consumed in $20 \%$ of the students in the city [42]. Other study which was done in Thailand in
2015 showed that $79 \%$ of students consumed breakfast each day, while one percent would never have breakfast [43].

The lack of breakfast among Tehran's students compared to other countries as well as other cities in Iran indicates the rising trend of these statistics in recent years. Different factors affect the students' breakfast consumption, including socioeconomic status $[42,44]$, living in urban or rural areas [42] parenting, familial environment [41] and the school environment $[45,46]$.

Social factors have effect on food and taste preferences, and unhealthy eating patterns are connected with low socioeconomic status [47].

According to previous studies, there was a negative relationship between high consuming breakfast rates and high BMI, the less eating breakfast, the more obesity would be find $[14,48,49]$, few studies have found that there is no significant relationship between breakfast and obesity or overweight [50].

In this study, the lack of breakfast in obese and overweight children was more common than normal weight children, but the difference was not statistically significant. Other factors affecting the overweight and obesity of children include socioeconomic conditions, nutritional habits, physical activity and a history of obesity or overweight in parents [14].

There is no obvious mechanism of the effect of taking breakfast on overweight and obesity, the risks of not having breakfast remaining unclear. Possible mechanisms have been proposed as follows: active kids after eating breakfast tend to enhance their physical activity and this reduce the risk of obesity. Taking bread and cereals fulfills the fiber protein in children's daily diet, as well as regulating glucose and insulin levels [51].

There is a connection between impaired development status and both poor school performance and intelligence quotient (IQ) [52]. The connection amongst convenient quality dietary consumption, brain size, and academic performance has been recorded [53]. This recommends that difference in IQ and academic performance human could be relevant to brain size. Although genetic and environmental factors such as socioeconomic and psychological factors could be effective [53,54].

Family status factors, for example, financial status and parents' level of education have been considered as 
indicators of children's academic development [25].

Although some previous studies have confirmed the significant relationship between breakfast consumption and improvement in academic performance [55-58], this result was not observed in this study.

Of course, the studies considered a set of scores obtained quantitatively, different test results and nonattendance at school. In this study, the scores of students according to the new method of school scoring were evaluated qualitatively. Perhaps this factor in this study makes the relationship between breakfast consumption and academic performance meaningless. According to previous studies, the relationship between breakfast and academic performance can be related to homeostatic mechanisms in maintaining the concentration of blood glucose $[59,60]$.

This has not been confirmed in some other studies [61,62], and other mechanisms, including the level of neurotransmitters, have been implicated [63]; socioeconomic indicators such as education and family income are also effective on academic performance $[64,65]$.

In this study, children with favorable academic status had a lower prevalence of obesity in comparison with children with undesirable academic status. However, this difference was not significant. Obesity is associated with cognitive damage and leads to impairment in cognition, memory, language, and attention by reducing of a factor called the brain-derived neurotropic factor (BDNF) in the hypothalamus (a factor that leads to the maturation of neurons in the brain) $[66,67]$.

Therefore, academic performance that is relevant to reading, writing and speaking is affected [68].

There are various limitation in this study which could be counted as follows: first of all, considering the cross-sectional nature of the study, it cannot be verified that there is a causal relationship between the dietary intake and the nutritional status of students with their academic status. Secondly, regarding the qualitative mean of a range of children in a desirable mid-point situation, there may be no significant difference between various weights groups in terms of academic performance related to this issue. It is suggested that according to the qualitative school scoring method, in future studies of academic performance, other parameters should be considered in addition to the average in order to provide a better picture of students' academic performance. Finally, we assesed frequency of breakfast consumption, not its nutrient content.

\section{Conclusions}

This study is the first study to examine the relationship between the habits of breakfast, nutritional status and academic performance of primary Iranian students with various socioeconomic conditions in this large sample.

Unlike previous studies, this result did not show a relationship between the average grade of elementary students with nutritional status and breakfast habits.

\section{References}

1. Chandra AR. An Investigation of Advertising on Media, Socio Economic, Gender, And Age Relationship With Obesity. POLI BISNIS. 2012;3:1-11.

2. Cherian AT, Cherian SS, Subbiah S. Prevalence of obesity and overweight in urban school children in Kerala, India. Indian Pediatr. 2012;49:475 -477.

3. Black MM, Hager ER, Le K, Anliker J, Arteaga SS, DiClemente $\mathrm{C}$, et al. Challenge! Health promotion/obesity prevention mentorship model among urban, black adolescents. Pediatrics. 2010;126:280-288.

4. Troiano RP, Flegal KM. Overweight children and adolescents: description, epidemiology, and demographics. Pediatrics. 1998;101(3Pt 2):497-504.

5. de Onis M, Blössner M, Borghi E. Global prevalence and trends of overweight and obesity among preschool children. Am J Clin Nutr. 2010;92:1257-1264.

6. Kelishadi R, Pour MH, Sarraf-Zadegan N, Sadry GH, Ansari R, Alikhassy H, et al. Obesity and associated modifiable environmental factors in Iranian adolescents: Isfahan Healthy Heart Program - Heart Health Promotion from Childhood. Pediatr Int. 2003;45:435-442.

7. Dorosty AR, Siassi F, Reilly JJ. Obesity in Iranian children. Arch Dis Child. 2002;87:388-391; discussion 388-391.

8. Bambra CL, Hillier FC, Moore HJ, Summerbell CD. Tackling inequalities in obesity: a protocol for a systematic review of the effectiveness of public health interventions at reducing socioeconomic inequalities in obesity amongst children. Syst Rev. 2012; $1: 16$.

9. Obesity: preventing and managing the global epidemic. Report of a WHO consultation. World Health Organ Tech Rep Ser. 2000;894:i-xii, 1-253.

10. Britain G. Healthy weight, healthy lives: a cross government strategy for England: HM Government; 2008.

11. Urrutia-Rojas X, Egbuchunam CU, Bae S, Menchaca J, Bayona M, Rivers PA, et al. High blood pressure in school children: prevalence and risk factors. BMC Pediatr. 2006;6:32.

12. Kopelman PG. Obesity as a medical problem. Nature. 2000;404:635-643.

13. Minet Kinge J, Morris S. Socioeconomic variation in the impact of obesity on health-related quality of life. Soc Sci Med. 2010;71:1864-1871.

14. Szajewska H, Ruszczynski M. Systematic review demonstrating that breakfast consumption influences body weight outcomes in children and adolescents in Europe. Crit Rev Food Sci Nutr. 2010;50:113-119.

15. WHO. Health topics, Nutrition . 2015.

16. Baranowski T, Mendlein J, Resnicow K, Frank E, WeberCullen K, Baranowski J. Physical Activity and Nutrition in Children and Youth: An Overview of Obesity Prevention. Preventive Medicine. 2000;31:S1-S10.

17. Rampersaud GC, Pereira MA, Girard BL, Adams J, Metzl JD. Breakfast habits, nutritional status, body weight, and academic performance in children and adolescents. J Am Diet Assoc. 2005; 105:743-760; quiz 761-2.

18. Karimi B, Sadat Hashemi M, Habibian H. Study of the breakfast habits and its relationship with some factors in Semnan (Iran) pupils. Koomesh. 2008;9:285-292.

19. Mendez MA, Adair LS. Severity and timing of stunting in the first two years of life affect performance on cognitive tests in late childhood. J Nutr. 1999;129:1555-1562. 
20. Basch CE. Breakfast and the achievement gap among urban minority youth. J Sch Health. 2011;81:635-640.

21. Bartfeld JS, Ahn HM. The School Breakfast Program strengthens household food security among low-income households with elementary school children. J Nutr. 2011;141:470475.

22. Waladkhani AR, Clemens M. Effects of nutrition on stress management. Vegetables, fruits and herbs in health promotion USA CRC. 18-2002:309.

23. Lien L. Is breakfast consumption related to mental distress and academic performance in adolescents? Public Health Nutr. 2007; 10:422-428.

24. Mortazavi Z, Roudbari M. Breakfast consumption and body mass index in primary, secondary and high school boys in Zahedan 2005-2006. Iranian Journal of Endocrinology and Metabolism. 2010;12:345-351.

25. Essien E, Haruna MJ, Emebu PK. Prevalence of Malnutrition and its Effects on the Academic Performance of Students in Some Selected Secondary Schools in Sokoto Metropolis. Pakistan Journal of Nutrition. 2012;11:609-613.

26. Ivanovic DM, Leiva BP, Pérez HT, Olivares MG, Diaz NS, Urrutia MS, et al. Head size and intelligence, learning, nutritional status and brain development. Head, IQ, learning, nutrition and brain. Neuropsychologia. 2004;42:1118-1131.

27. Taras H, Potts-Datema W. Obesity and student performance at school. J Sch Health. 2005;75:291-295.

28. St-Onge MP, Keller KL, Heymsfield SB. Changes in childhood food consumption patterns: a cause for concern in light of increasing body weights. Am J Clin Nutr. 2003;78:1068-1073. 29. Briggs M, Safaii S, Beall DL; American Dietetic Association; Society for Nutrition Education; American School Food Service Association. Position of the American Dietetic Association, Society for Nutrition Education, and American School Food Service Association--Nutrition services: an essential component of comprehensive school health programs. J Am Diet Assoc. 2113; 103:505-514.

30. Taras H. Nutrition and student performance at school. J Sch Health. 2005;75:199-213.

31. Sadrzadeh-Yeganeh H, Angoorany P, Keshavarz S, Rahimi A, Ahmady B. Comparison of two nutrition education techniquies on breakfast-eating practice in primary school girls, Tehran. Journal of School of Public Health and Institute of Public Health Research. 2006;4:65-72.

32. Kuczmarski RJ, Ogden CL, Guo SS, Grummer-Strawn LM, Flegal KM, Mei Z, et al. 2000 CDC Growth Charts for the United States: methods and development. Vital Health Stat 11. 2002;(246):1-190.

33. Hall A, Khanh LN, Son TH, Dung NQ, Lansdown RG, Dar DT, et al. An association between chronic undernutrition and educational test scores in Vietnamese children. Eur J Clin Nutr. 2001;55:801-804.

34. Opoola F, Adebisi SS, Ibegbu AO. The study of nutritional status and academic performance of primary school children in Zaria, Kaduna State, Nigeria. Annals of Bioanthropology. 2016;4:96.

35. Rastogi P, Nagesh KR, Yoganarasimha K. Estimation of stature from hand dimensions of north and south Indians. Leg Med (Tokyo). 2008;10:185-189.

36. Duyar İ, Pelin C. Estimating body height from ulna length: need of a population-specific formula. Eurasian journal of Anthropology. 2010;1:11-17.
37. Soleimani N, khani S. Effect of breakfast eating on the cognitive performane and educational achievement of the fourth grade student of elementary school in 2010-2011. Research in curriculm planing. 2014, 11, 13. 139-150

38. Alavi Naeini S, Jazayeri S, Moghaddam Banaem N, Afrooz GA. The effects of taking snacks on the learning ability and educational achievement of elementary school children, 199798. Tehran University Medical Journal TUMS Publications. 2000;58:38-44.

39. Soheiliazad AA, Nourjah N, Aalamdar E. Surveying the food intake of primary school students in Tehran. Research in Medicine. 2005;29:165-168.

40. Soheili Azad A, Nourjah N, Norouzi F. Survey the eating pattern between elementary students in Langrood. Journal of Guilan University of medical sciences. 2007;16:36-41.

41. Vaghari G, Keshtkar AA, Shomali L, Aslani H, Moradian H, Kazemi S. The Status of Breakfast Consumption among Primary School Children in the North of Iran. Payesh. 2012;11:327-336.

42. Gross SM, Bronner Y, Welch C, Dewberry-Moore N, Paige DM. Breakfast and lunch meal skipping patterns among fourthgrade children from selected public schools in urban, suburban, and rural Maryland. J Am Diet Assoc. 2004;104:420-423.

43. Sirichakwal PP, Janesiripanich N, Kunapun P, Senaprom $\mathrm{S}$, Purttipornthanee S. Breakfast consumption behaviors of elementary school children in Bangkok metropolitan region. Southeast Asian J Trop Med Public Health. 2015;46:939-948.

44. Shi Z, Lien N, Kumar BN, Holmboe-Ottesen G. Sociodemographic differences in food habits and preferences of school adolescents in Jiangsu Province, China. Eur J Clin Nutr. 2005;59:1439-1448.

45. West P. Health inequalities in the early years: is there equalisation in youth? Soc Sci Med. 1997;44:833-858.

46. West P, Sweeting H. Evidence on equalisation in health in youth from the West of Scotland. Soc Sci Med. 2004;59:13-27.

47. Groth M, Christensen L, Knudsen V. Social Differences in Children's Dietary Habits, Physical Activity and Overweight, and Adults' Dietary Habits. Søborg: Division of Nutrition, National Food Institute, Technical University of Denmark. 2013.

48. Sjöberg A, Hallberg L, Höglund D, Hulthén L. Meal pattern, food choice, nutrient intake and lifestyle factors in The Göteborg Adolescence Study. Eur J Clin Nutr. 2003;57:1569-1578.

49. Harding S, Teyhan A, Maynard MJ, Cruickshank JK. Ethnic differences in overweight and obesity in early adolescence in the MRC DASH study: the role of adolescent and parental lifestyle. Int J Epidemiol. 2008;37:162-172.

50. Vågstrand K, Barkeling B, Forslund HB, Elfhag K, Linné $\mathrm{Y}$, Rössner S, et al. Eating habits in relation to body fatness and gender in adolescents--results from the 'SWEDES'study. Eur J Clin Nutr. 2007;61(4):517-525.

51. Giovannini M, Verduci E, Scaglioni S, Salvatici E, Bonza M, Riva E, et al. Breakfast: a good habit, not a repetitive custom. J Int Med Res. 2008;36:613-624.

52. Organization PAH. Health statistics from the Americas: World Health Organization; 1998.

53. Sternberg RJ. Handbook of intelligence: Cambridge University Press; 2000.

54. Wickett JC, Vernon PA, Lee DH. Relationships between factors of intelligence and brain volume. Personality and Individual Differences. 2000;29:1095-1122.

55. Powell CA, Walker SP, Chang SM, Grantham-McGregor SM. Nutrition and education: a randomized trial of the effects 
of breakfast in rural primary-school children. Am J Clin Nutr. 1998;68:873-879.

56. Boey C, Omar A, Arul Phillips J. Correlation among academic performance, recurrent abdominal pain and other factors in Year6 urban primary-school children in Malaysia. J Paediatr Child Health. 2003;39:352-357.

57. Kleinman RE, Hall S, Green H, Korzec-Ramirez D, Patton K, Pagano ME, et al. Diet, breakfast, and academic performance in children. Ann Nutr Metab. 2002;46 Suppl 1:24-30.

58. Kim HY, Frongillo EA, Han SS, Oh SY, Kim WK, Jang YA, et al. Academic performance of Korean children is associated with dietary behaviours and physical status. Asia Pac J Clin Nutr. 2003;12:186-192.

59. Pollitt E, Mathews R. Breakfast and cognition: an integrative summary. Am J Clin Nutr. 1998;67:804S-813S.

60. Michaud C, Musse N, Nicolas JP, Mejean L. Effects of breakfast-size on short-term memory, concentration, mood and blood glucose. J Adolesc Health. 1991;12:53-57.

61. Cromer BA, Tarnowski KJ, Stein AM, Harton P, Thornton DJ. The school breakfast program and cognition in adolescents. J Dev Behav Pediatr. 1990;11:295-300.

62. Cueto S, Jacoby E, Pollitt E. Breakfast prevents delays of attention and memory functions among nutritionally at-risk boys. Journal of Applied Developmental Psychology. 1998;19:219-233. 63. Pollitt E, Cueto S, Jacoby ER. Fasting and cognition in well- and undernourished schoolchildren: a review of three experimental studies. Am J Clin Nutr. 1998;67:779S-784S.

64. Arnold DH, Doctoroff GL. The early education of socioeconomically disadvantaged children. Annu Rev Psychol. 2003;54:517-545.

65. Bradley RH, Corwyn RF. Socioeconomic status and child development. Annu Rev Psychol. 2002;53:371-399.

66. Gray J, Yeo GS, Cox JJ, Morton J, Adlam AL, Keogh JM, et al. Hyperphagia, severe obesity, impaired cognitive function, and hyperactivity associated with functional loss of one copy of the brain-derived neurotrophic factor (BDNF) gene. Diabetes. 2006;55:3366-3371.

67. Yau PL, Castro MG, Tagani A, Tsui WH, Convit A. Obesity and metabolic syndrome and functional and structural brain impairments in adolescence. Pediatrics. 2012;130:e856-e864 .

68. Kim JH, So WY. Association between overweight/obesity and academic performance in South Korean adolescents. Cent Eur J Public Health. 2013;21:179-183. 